\title{
Behavioral Problems in Offspring of Bipolar Mothers
}

\author{
S. Mohammad Moosavi ${ }^{1}$, Mahshid Ahmadi ${ }^{2}$, Mani B. Monajemi ${ }^{3}$, \\ ${ }^{1}$ Department of Psychiatry, Mazandaran University of Medical Sciences, Sari, Iran \\ ${ }^{2}$ Department of Communication Medicine, Mazandaran University of Medical Sciences, Sari, Iran \\ ${ }^{3}$ Department of Clinical Psychology, University of Tehran, Tehran, Iran
}

\section{Email address:}

mmosavi@mazums.ac.ir(S. M. Moosavi),m.ahmadi@mazums.ac.ir (M. Ahmadi), mani.b.monajemi@warwickgrad.net (M. B. Monajemi), mani.b.monajemi@ut.ac.ir (M. B. Monajemi)

\section{To cite this article:}

S. Mohammad Moosavi, Mahshid Ahmadi, Mani B. Monajemi. Behavioral Problems in Offspring of Bipolar Mothers. European Journal of Preventive Medicine. Vol. 3, No. 6, 2015, pp. 167-171. doi: 10.11648/j.ejpm.20150306.11

\begin{abstract}
Background and purpose: The prevalence of behavioral problems in children with mentally ill parents may be higher compared to children with mentally healthy parents. This study was carried out to assess the behavioral problems in children with bipolar mothers. Material and methods: This case-control study was conducted between 50 children (6-11 years) of mothers with bipolar I disorder as a case group and 50 children of healthy mothers as control group in Sari, Iran, during 2011-13. With psychiatric interview based on DSM-IV-R and Minnesota Multiphasic Personality Inventory (MMPI), bipolar disorder in mothers was confirmed and other prominent psychiatric disorders were ruled out. The psychological health of control mothers was confirmed using psychiatric interview and general health questionnaire (GHQ). The behavioral problems of children in two groups were compared using Achenbach child behavior questionnaire. Data were analyzed using SPSS-19, Chi- Square and Student's t-test. Results: Somatic complaints, anxiety and depression, social problems, externalization and internalization scores and also behavioral problems total scores were significantly higher in case group compared to control group $(\mathrm{P}<0.05)$. No significant differences between case group and control group were mentioned with respect to isolation, attention problems, thought problems, antisocial behaviors. Conclusion: Psychiatric and behavioral problems in children with bipolar mothers were higher, compared to children of healthy mothers. Child psychological counseling and psychiatric management in along to mothers' treatment is advisable.
\end{abstract}

Keywords: Achenbach Child Behavior Questionnaire (ACBQ), Bipolar Disorder Type I, Child Behavioral Problems

\section{Introduction}

Psychiatric Disorders influences are not just limited to the patient himself, but it will also affect his family and society (1). Behavioral problems in different societies have rather same prevalence (2). As most of the children with behavioral problems reach adulthood, their problems will fade away partly or totally, however in some cases the problem may sustain (3). Children with psychiatric disorders diagnosed parents have relatively more behavioral problems (4). Literatures suggest that children with depressed mothers are much more prone to behavioral disorders (5). Physical/Mental illness of parents can cause behavioral disorders in children $(6,7,8)$. In recent decades, although the financial status of household has become more stable but the behavioral disorders of children have not been mollified (9). Various hypotheses have been proposed with respect to behavioral disorders and it appears plausible that holding on to one hypothesis will not justify the occurrence of this spectrum of disorders (10). Different hypotheses have discussed varied modalities of abnormal behavior among children and adolescents such as: Critical period of adolescence, substance abuse, job-related stress of parents, passive parents, psychotic parents, smoking habits of parents, parents addiction, cannabis abuse, chaotic family dynamic, mother's depression, life stressful events, antisocial personality disorder (11-20). In another sense, in assessing the correlation between mother's psychiatric disorders and children emotional/behavioral problems, genetic factor and neurobiological changes have been noted (21). Some of these factors are: Reducing size in Prefrontal grey matter and Gyrus Cinguli, impairment in regulation of prefrontal cortex, amygdala hyper-sensitivity, reduced amount of serotonin in prefrontal cortex, impairment in adjustment of neuropeptides equilibrium such as oxytocin, opioids and vasopressin (2229). A lot of researches have been conducted in order to study 
the children behavioral problems; in this study Achenbach Child Behavior Questionnaire (ACBQ) has been used. A few number of studies regarding children having bipolar mothers experiencing behavioral disorders have been conducted and as most of these children are not under clinical treatment, their issues remain unresolved and more likely they would sustain for so many years. Furthermore, it is advisable to implement therapeutic intervention among these children as soon as possible in order to mitigate adverse consequences. Impeccable timing could led to decrease in unfavorable social consequences and family issues. Thus, this research was conducted to assess the behavioral problems among children with bipolar mothers.

\section{Material and Methods}

This case-control study was conducted between 50 offspring (6-11years old) of mothers with Bipolar Disorder Type I as case group and 50 children of healthy mothers as control group in Sari/Iran during 2011-13. People were chosen via purpose sampling method.

Exclusion Criteria: After assessing past personal history, past medical history, conducting psychiatric interview and physical and neurological examination, if child had a serious somatic/psychiatric illness or was diagnosed as mental retard, child was excluded from the research. The procedure was continued until each of groups reached 50 people. With conducting an interview based on of DSM-IV$\mathrm{R}$ and Minnesota Multiphasic Personality Index (MMPI), bipolar disorder type I in mothers was confirmed and other prominent psychiatric disorders were ruled out. The psychological health of mothers in control group was confirmed by psychiatric interview and general health questionnaire (GHQ). The behavioral problems in two groups of children were compared using ACBQ. After clarifying mothers about the study and reassuring them about the anonymity of questionnaires and confidentiality of their information, written informed consents were obtained. ACBQ filled by mothers and if the mother was illiterate, research assistant completed the questionnaire instead of her.

ACBQ was created in 1979 for assessing mental disorders and children's adaptation with their environment (30). This test contains 113 questions with $0-2$ score. In absence of maladaptive behavior, the score would be 0 and in an existence, the score 2 is given. Total score less than 66 is considered as normal, $66-70$ is borderline and more than 70 is pathologic. The scales are: isolation, somatic complaints, anxiety and depression, social problems, thought problems, attention problems, crime and aggressive behavior. Validity of the research instrument assessed and confirmed by content's value method. Reliability in 1381 confirmed by Tehrani and colleagues (31) in Research institute of cognitive sciences with the aid of norm-finder form. The data analyzed through SPSS-19, Chi-Square and Student t-test. In this research degree of meaningfulness considered to be 0.05 .

\section{Results}

In this study 100 children including 47 girls and 53 boys (6-11 years old) participated. Regarding gender distribution in children's group with healthy mother, $47 \%$ were girls and $53 \%$ boys. In a children's group with bipolar mothers, the distribution percentage between boys and girls were $55 \%$ and $45 \%$ respectively. Thus, there was not a meaningful difference between two groups respecting to gender distribution. In case-group average age was 9.70 \pm 2.70 and in control group average was $9.80 \pm 2.80$ and the difference was not meaningful. The children of bipolar mothers had more internalization and externalization score comparing to control group (Table 1).

The scores of somatic complaints, in case-group were noticeably higher comparing to control group; anxiety and depression had a meaningful rise. Social problems were noticeably higher in case group comparing to control group and this last item had the most difference between groups $(\mathrm{P}<0.05)($ Table 1). Regarding social isolation and crime scale, no noticeable difference was observed. Thought problems and Attention problems scale didn't have noticeable difference (Table 1). In bipolar mothers group, total score of children with behavioral problems had an evident increase $(\mathrm{p}<0.001)($ Table 2$)$.

Table 1. Mean/SD of mental disorders of children with or without bipolar mothers.

\begin{tabular}{llll}
\hline $\begin{array}{l}\text { Mental Disorders } \\
\text { Questionnaire }\end{array}$ & $\begin{array}{l}\text { Case Group } \\
\text { (Mean, SD) }\end{array}$ & $\begin{array}{l}\text { Control group } \\
\text { (Mean, SD) }\end{array}$ & P value \\
\hline Social Isolation & $4.12 \pm 2.34$ & $3.11 \pm 1.3$ & 0.078 \\
Somatic Complaints & $2.14 \pm 1.34$ & $0.11 \pm 0.3$ & 0.045 \\
Anxiety/Depression & $6.72 \pm 2.34$ & $3.45 \pm 0.3$ & 0.023 \\
Social Problems & $3.22 \pm 1.34$ & $3 \pm 0.3$ & 0.012 \\
Thought problems & $1.22 \pm 0.14$ & $1.01 \pm 0.2$ & 0.098 \\
Attention problems & $1.12 \pm 2.34$ & $1.11 \pm 0.3$ & 0.089 \\
Crime & $3.18 \pm 1.24$ & $2.91 \pm 0.3$ & 0.087 \\
Internalization & $13.12 \pm 3.12$ & $7.4 \pm 1.3$ & 0.001 \\
Externalization & $14.13 \pm 2.3$ & $9.13 \pm 3.02$ & 0.001 \\
Total Issues & $27.12 \pm 2.3$ & $16.9 \pm 4.4$ & 0.001 \\
\hline
\end{tabular}

Table 2. Frequency of mental disorder of children with normal and bipolar mothers.

\begin{tabular}{llll}
\hline $\begin{array}{l}\text { Mental Disorders } \\
\text { Questionnaire }\end{array}$ & $\begin{array}{l}\text { Group with } \\
\text { Bipolar mothers } \\
\text { (Percentage) }\end{array}$ & $\begin{array}{l}\text { Group with } \\
\text { normal Mothers } \\
\text { (Percentage) }\end{array}$ & P Value \\
\hline Without disorder & $39 \%$ & $73 \%$ & 0.001 \\
Borderline & $35 \%$ & $19 \%$ & 0.001 \\
With Disorder & $26 \%$ & $8 \%$ & 0.001 \\
\hline
\end{tabular}

\section{Discussion}

Based on findings of this study, score of behavioral problems among children with bipolar mothers in scales of somatic complaints, anxiety and depression, social problems, internalization problems, externalization problems and total problems were more than control group. However, regarding attention problems, thought problems and delinquency, there weren't conspicuous differences between groups.

A lot of studies regarding risk of mental illness in offspring 
of parents with severe mental or physical problems, impaired relationship of mother and child, mother's emotional mutilation, compromised working schedule of mother, mother's social problems, mother's eating disorder, mother's depression and relation of biologic factors have been conducted (32-39). Nonetheless, the main feature of previous researches, which have been conducted so far, is that except depression and schizophrenia, it hasn't been focused on a specific psychiatric disorder in mother and its influence on child's abnormal behavior. Another common feature between studies is that they have studied the disorders in general and even if they focused on specific topic, in most cases aggressive behavior or substance abuse in children and adolescents were targeted as abnormal behavior (40) and in contrast to this study they have less focused on categorizing these problems. The findings of this study are comparable with the study of Bartels and colleagues (41) and Halpern (42) who have assessed the problems of internalization and externalization. Although, in their studies these two factors have been noticed narrowly. Weaver and colleagues (32) and olive and colleagues (43), assessed mother's psychiatric problems and its effects on child's behavior, their results are concordant with current study. In aforementioned studies, mother's psychiatric problems have been discussed in general and bipolar disorder hasn't been scrutinized effectively. In another study conducted by Ostiguy and colleagues (44) internalization and externalization and communication problems of the children with bipolar parents reported and the result of the study was similar to the result of the current study. Nonetheless, in current study other problems like depression/anxiety and somatoform problems in children with bipolar mothers have been noticed. Possibly, difference in results has stemmed from the fact that in aforementioned study both of the parents were studied while in current study we focused on a relationship between mother and child specifically because of the crucial impact of mother on child between critical age of 6-11 years old. Thus, mother's behavioral impairment would have much more impact on children. Garcia and colleagues (45) have studied impact of parents' psychiatric impairments on children behavioral abnormality and they have concluded that anxiety, depression and attention disorders are existed in half of the children with psychiatric impaired parents. Increase in anxiety and depression scales is being noticed while attention disorders didn't have conspicuous rising and this can result from using different research instruments. Another reason could be that, in Ostiguy's study, disorders of both parents were studied while in current study we focused only on mother's psychiatric problems. In Moosavi and colleagues study (46) behavioral problems in children with psychiatric impaired mother reported higher than those with normal mothers. In their study, externalization and internalization, physical complaints and social issues were reported higher and the difference was meaningful, however mentioned study was conducted among mothers with OCD. The Results of current study is consistent with the result of the study conducted by Daniel and Colleagues (52). Although in their study, in addition to Bipolar disorder they focused on other serious psychiatric disorders such as schizophrenia and major depressive disorder. In their study, they discussed that Offspring of parents with serious mental illness are at increased risk for a range of psychiatric disorders and one third of them may develop a serious mental illness by early adulthood (52). Korschun (53) speculated that temperament and behavior of toddlers whose mothers have bipolar disorder shows that toddlers who struggle with frustration, restraint and negative emotions may be at increased risk for behavioral problems over time.

Another results in other studies $(21,18,13,4-6)$ were assessed, which were similar to the result of current study. Internalization and externalization scale's results in former studies (47-49) are consistent with the result of current study. In assessing various findings, study, which concentrates on mother's psychiatric problems and its effects specifically on physical, complaints and thought problems, weren't found. Based on the results of this study and other studies, as aforementioned, the behavioral problems in children with psychiatric impaired mothers are more. Paying attention to behavioral issues and dividing them into different scales is vital because in primary and secondary intervention can be focused on a specific problem and this will save time and energy. In some cases, which we have limited human resource or clinical facilities it can be effective, furthermore it can minimize our costs and it will optimize our therapeutic process. These children have more educational problems (50) and this can be resulted from symptoms and physical complaints and depression and anxiety. Furthermore, social issues can cause educational problems in these children.

To put the whole idea in perspective, it can be concluded that it is vital to diagnose the type and severity of these problems among children. It has been noticed that short-term clinical intervention is more effective on improving child behavior and indirectly it will affect mother's behavior (51). Additionally, effects of mother's behavioral disorders can remain in child and it can be passed to next generation (44). Hence, it is important to pay attention to these problems.

\section{References}

[1] Bradford R. Quality of Life in Young People: Rating and Factor Structure of the Quality of Life Profile, Adolescent Version. Journal of Child and Adolescent Psychiatry. 2002; 25:261-274

[2] Rescorla L, Achenbach TH, Lvanova MY, Dumenci L, Almqvist F, Bilenberg N, et al. Behavioral and Emotional Problems Reported by Parents of Children Age 6 to 16 in 31 Societies. J Emot Behav Disord. 2007;15(3):130-42.

[3] Gershuny B S, Baer L, Radomsky AS, Wilson K A, Jenike MA. Connection among Symptoms of Obsessive-Compulsive Disorder and Posttraumatic Stress Disorder: A Case Series. Behav Res Ther. 2003; 41: 1029- 41.

[4] Wamboldt MZ, Reiss D. Exploration of Parenting Environments in the Evolution of Psychiatric Problems in Children. Am J Psychiatry. 2006;163:951- 3. 
[5] Weller EB, Rowan A, Elia J, Weller RA. Aggressive Behavior in Patients with attention- deficit htperactivity disorder, Conduct Disorder and pervasive devwlopmental disorders. J Clin Psychiatry. 1999;60(15):5-11.

[6] Jung HH, Kim CH, Chang JH, Park YG, Chung SS, Chang JW Bilateral Anterior Cingulotomy for Refractory ObsessiveCompulsive Disorder: long Term Follow-up Results. Stereotact Funct Neurosurg. 2006;84: 144-89.

[7] Cohen BE, Marmar CR, NeylanTC, Schiller NB, Ali S, Whooley MA.Posttraummatic Stress Disorder and Healthrelated Quality of Life in Patients with Coronary Heart Disease: finding from the heart and soul study. Arch Gen Psychiatry. 2009;66(11):1214-20.

[8] Sutor B, Hansen MR, Black JL. Obsessive-Compulsive Treatment in Patients with Down Syndrome: a case series. Down Syndr Res Pract.2006;10:1-13.

[9] Scott S. National Dissemination of Effective Parenting Programs to Improve Child Outcomes. $\mathrm{Br} J$ Psychiatry.2010;196 (1):1-3.

[10] Brook DW, Brook JS, Rosen Z, De La Rosa M, Montoya ID, Whiteman M. Early Risk Factor for Violence in Colombian Adolescents. Am J Psychiatry.2003;160:1470-78.

[11] Rosenzweig JM, Bernnan EM, Huffsutter K, Bradley JR. Child Care and Employed Parents of Children with Emotional or Behavioral Disorders. J Emot Behav Disord. 2008;16(2):78-89.

[12] Donatelli JA, Seidman LJ, Goldstein JM. Tsuang MT, Buka SL. Children of Parents with Affective and None-affective Psychosis: A Longitudinal Study of Behavior Problems. Am J Psychiatry. 2010;167(11):1331-8.

[13] Keyes M, Legrand LN, Lacono WG, McGue M. Parental Smoking and Adolescent Problem Behavior: An Adoption Study of General and Specific Effects. AM J Psychiatry. 2008;165(10):1338-44.

[14] Moss HB, Lynch KG, Hardie TL, Baron DA. Family Functioning and Peer Affiliation in Children of Fathers with Antisocial Personality Disorder and Substance Dependence: Association with Problem Behaviors. Am J Psychiatry.2002;159(4):607-14.

[15] Monshouwer K, VAN Dorsselaer S, Verdurmen J, Bogt TT, DE Graaf R, Volleberg W. Cannabis Use and Mental Health in Secondary School Children: Finding from a Dutch Survey. Br J Psychiatry. 2006;188:148-53.

[16] Asasthi A. Preserve and Strengthen Family to Promote Mental Health. Indian J Psychiatry. 2010;52(2):113-126.

[17] Pilowsky DJ, Wickramaraine PJ, Rush A, Hughes CW, Gerber J, Mally E, et al. Children of Currently Depressed Mothers: a STAR*D Ancillary Study. J Clin Psychiatry. 2006;67(1):12636.

[18] Aggarwal S, Prabhu CH, Anand LC, Kotwal LC. Stressful Life Events among Adolescents: The Development of a New Measure. Indian J Psychiatry.2007;49(2):96-102.

[19] Boisjoli R, Vitaro F, Lacuoure E, Baker ED, Tremblay RE. Impact and Clinical Significance of a Preventive Intervention for Disruptive Boys:15- Tear Follow-up. $\mathrm{Br}$ J Psychiatry.2007;191:415-19.
[20] Rutter M. Child Psychiatric Disorders: Measures Causal Mechanism a d Interventions. Arch Gen Psychiatry. 1997;54(9):785-9.

[21] Radaue J, VAN den Heuvel OA, SSurguladze S, Mataix- Cols D. Meta-analytical Comparison of Voxel-based Morphometry Studies in Obsessive- Compulsive Disorders Vs other Anxiety Disorders. Arch Gen Psychiatry. 2010;67(7):701-11.

[22] Siever LJ. Neurobiology of Aggression and Violence. Am J Psychiatry.2008;165(4):429-42.

[23] Siever LJ, Weinstein LN. The Neurobiology of Personality Disorders: Implications of Psychoanalysis. Am J Psychoanal Assoc.2009;57(2):361-98.

[24] Stanley B, Siever LJ. The Interpersonal Dimention of Borderline Personality Disorder: toward a Neuropeptide Model. Am J Psychiatry.2010;167(1):24-39.

[25] young SN. The Neurobiology of Human Social Behaviour: an Important but Neglected Topic. J Psychiatry Neurosci. 2008;33(5):391-2.

[26] Terao T. Aggression, Suicide and Lithium Treatment. Am J Psychiatry. 2007;156(10):1356-7.

[27] Berman ME, Mc Clokey MS, Fanning JA, Schumache JA Coccaro EF. Serotonin Augmentation Reduces Response to Attack in Aggressive Individuals. J Psychol Sci. 2009;20(6):714-30.

[28] Kebir O, Tabbane K, Sengupta S, Joober R. Candidate Genes and Neuropsychological Phenotypes in Children with ADHD: Review of Association Studies. J Psychiatry Neurosci. 2009;34(2);88-101.

[29] Bayer JK, Sanson AV, Hemphill SA. Children Mood, Fears and Worries: Development of an Early Childhood Parent Questionnaire. J Emot Behav Disord.2006;14(1):41-9.

[30] Uhing BM, Mooney P, Ryser GR. Differences in Strength Assessment Scores for Youth with and without ED across the Youth and Parent Rating Scales of the BERS-2. J Emot Behav Disord. 2005;13(3):181-7.

[31] Mohammadi MR, Mesgarpour B, Sahimi Izadian E. Psychological Tests and Psychiatric Medication in Children and Adolescents. $1^{\text {th }}$ ed, Tehran: Teymoorzadeh. 2007; pp:1618.(Persian).

[32] Weaver CM, Shaw DS, Dishion TJ, Wilson MN. Parenting Self-efficacy and Problem Behavior in Children at High risk for Early Conduct Problem: The Medication Role of Maternal Depression. J Infant Behav Dev. 2008;31(4):594-605.

[33] Ary DV, Duncan TE, Duncan SC, Hops H. Adolescent Problem Behavior: the Influence Of Parents and Peers. Behav Res Ther. 2008;31(4): 549-607.

[34] Bullock BM, Dishion TJ. Family Processesand Adolescent Problem Behavior Integrating Relationship Narratives into Understanding Development and Change. J Am Acad Child Adol Psychiatry. 2007;46(3):396-407.

[35] Daniel SS, Grzywacz JG, Leerks E, Tucker J, Han WJ. Nonstandard Marernal Work Schedules during Infancy: Implications for Childrens' early Behavior Problems. Infant Behav Dev. 2009; 32(2):195-207.

[36] Valiente C, Eiseiser M, Spinard TL, Riser M, Cumberland A, Losoya SH, et al. Relationship among Mothers' Expressivity, Childrens' Effortful Control and their Problem Behaviors: a four Year Longitudinal Study. Emotion. 2006;6(3): 459-72. 
[37] Coulthard H, Blissett J, Harris G, The Relationship between Parental Eating Problems and Childrens' Feeding Behavior: a Selective Review of the Literature. Eat Behav. 2004; 5(2):1035 .

[38] Moosavi M, Ahmadi M. Behavioral Disorders in Children with Major Depressive Mothers. J GorGan Uni Med Sci. 2012;14(3): 115-20(Persian).

[39] Pakashati L. Childrens and Adolescents' Aggressive Behavior in Context: yhe Development and Application of Aggressive problem- solving Strategies. Aggress Viol Behav. 2005;5(5): 467-90.

[40] Chun H, Mobley M. Gender and Grade-level Comparison in the Structure of Problem Behaviors among Adolescents. J Adol. 2010;33(1):197-207.

[41] Bartels M, Hudziak JJ, Boomsma DI. A study of Parent Rating of Internalizing and Externalizing Problem Behavior in 12 Year-old Twin. J Am Acad Child and Adol Psychiatry. 2003;42(11):1357-59.

[42] Halpern LF. The Relations of Coping and Family Environment to Preschoolers Problem Behavior. J App Dev Psychol. 2004;25(4):399-421.

[43] Olive PH, Guerin DW, Coffman JK. Big Five Personality Traits, Parenting Behaviors and Adolescents' Behavior Problems: a Medication Model. J Indiv Diff. 2009;47(6):631-6.

[44] Ostiguy CS, Ellenbogen MA, Hodgin S. Personality of Parents with Bipolar Disorder and Interpersonal Functioning among their Offspring: a Prospective 10 Year Study. J Dev Psychopath. 2012;24(2): 573-87.

[45] Garcia- Amador M, De La Serna E, Vila M, Romero S, Valenti M, Sanchez - Gistau V, et al. Parents with Bipolar Disorder: Are Disease Charecteristics good Predictors of Psychopathology in Offspring JEuro Psychiatry. 2012; http://informahealthcare.com/doli/abs/10.3109/1365101.
[46] Moosavi M, Ahmadi M. Comparative Survay on Children Behavior Problems From Obsessive- Compulsive and Healthy Mothers. J Mazand Univ Med Sci. 2012;22(86):1038(Persian).

[47] Van Meurs I, Reef J, Verhulst FC, Van der Ende J. Integrational Transmission of Child Problem Behaviors: a Longitudinal Population- Based Study. J Am Child Adol Psychiatry. 2009;48(2): 138-45.

[48] Van Aken C, Junger M, Verhoeven M, Van Aken MA, Dekovic M. The Longitudinal Relation Between Parenting and Toddlers' Attention Problem and Aggressive Behaviors. J Infant Behav Dev. 2008;31(3): 432-46.

[49] Eiden RD, Edward EP, Leonard KE. A Conceptual Model for the Development of Externalizing Behavior Problem among Children of Alcoholic Families Role of Parenting and Children's Self regulation. J Dev Psychol. 2007;43(5):1187201.

[50] Gardner F, Shaw DS, dishion TJ. Randomized Prevention Trial of Conduct Problems: Effects of Proactive Parenting and Links to Toddler Disruptive Behaviors. J Fam Psychol .2007; 21(3):398-406.

[51] Colsmam M, Wulfert E. Conflict Resolution Style as an Indicator of Adolescents' Substance Use and other Problem Behaviors. J Addict Behav. 2002;27(4):633.

[52] Daniel Rasic; Tomas Hajek; Martin Alda; Rudolf Uher. (2015). Risk of Mental Illness in Offspring of Parents With Schizophrenia, Bipolar Disorder, and Major Depressive Disorder A Meta-analysis of Family High-Risk Studies. Available: http://www.medscape.com/viewarticle/819416. Last accessed Sep 2015.

[53] Holly Korschun.(2015). At-risk children of mothers with bipolar disorder may benefit from early intervention. Available: http://medicalxpress.com/news/2015-06-at-riskchildren-mothers-bipolar-disorder.html. Last accessed Sep 2015. 